\title{
DA SUBSERVIÊNCIA À SUBVERSÃO: SHAKESPEARE NO CINEMA SILENCIOSO
}

\author{
Marcel Vieira Barreto Silva ${ }^{1}$
}

\begin{abstract}
Resumo: Este artigo tem o objetivo de analisar filmes do período silencioso (1895-1929) que utilizaram a literatura dramática de William Shakespeare como fonte. Encenando diferentes procedimentos de apropriação, condizentes às capacidades narrativas de cada período, esses filmes apresentam maneiras amplamente variadas de atualizar o teatro shakespeariano, desde o cinema de atrações - e sua estética de mostração -, até a releitura paródica e a crítica metatextual. Nesse sentido, são obras que, analisadas conjuntamente, auxiliam no entendimento dos modos de adaptação de Shakespeare à cultura audiovisual do século XX, através das diversas ingerências sociais, culturais, econômicas e estéticas envolvidas no processo.
\end{abstract}

Palavras-chave: Shakespeare no cinema; Cinema silencioso; Adaptação Cinematográfica.

\begin{abstract}
This paper intends to analyze films from the silent era (1895-1929) which used Shakespeare's dramatic literature as a source. Staging different appropriating procedures, accordingly with the narrative capabilities of each moment, these films show widely variable ways to actualize Shakespearean theater, from cinema of attractions - and its showing aesthetics - to parodic readings and metatextual criticisms. In this sense, these are works that, once analyzed as a whole, help to understand the modes of adaptation of Shakespeare to 20th century audiovisual culture, considering the different interference of society, culture, economics and aesthetics involved in the process.
\end{abstract}

Key-words: Shakespeare on cinema; Silent Cinema; Cinematographic Adaptation.

\section{Introdução}

A primeira aparição de Shakespeare no cinema ocorreu ainda em fins do século XIX, em 1899, apenas quatro anos após a exibição inaugural dos irmãos Lumière. O famoso ator teatral Sir Herbert Beerbohm Tree encenava a peça King John no Her Magesty's Theater, em Londres, quando se juntou a William Kennedy-Laurie Dickson (antigo colaborador de Thomas Edison) e realizou algumas tomadas da peça em um curta-metragem de um rolo. A cena foi captada com uma Biograph Camera, restrita ao padrão $68 \mathrm{~mm}$, em um estúdio ao arlivre, de propriedade da British Mutoscope and Biograph Company, junto ao aterro do rio

\footnotetext{
${ }^{1}$ Professor Assistente do Curso de Cinema e Audiovisual da Universidade Federal do Ceará. Email: marcelvbs@hotmail.com
} 
Tâmisa. No fundo de cena, vemos um pano em cujo desenho se percebe um jardim palaciano, cercado de pilastras e portas ao fundo, que dão uma ilusão (teatral, não cinematográfica) de perspectiva. Essa cenografia fazia parte da encenação da peça, cuja filmagem tentava emular. Atualmente, resta apenas um fragmento da filmagem original, com pouco mais de um minuto. Nele, vemos o momento da morte de King John, na sétima cena do quinto ato da peça, com a câmera estática posicionada de frente, mostrando a ação num plano geral. A poltrona real ocupa o centro do quadro e nela o rei agoniza, rodeado pelo príncipe Henry, pelo conde de Pembroke e por Robert Bigot, que observam a ação. O fragmento silencioso, mais do que tentar representar a trama da peça shakespeariana - ou mesmo uma mínima redução com início, meio e fim -, funcionava como uma espécie de exibição promocional da peça. De acordo com Judith Buchanan (2005: 22), "provavelmente acompanhado de duas ou três cenas filmadas da mesma produção teatral, ele foi exibido durante o outono e o inverno de 1899 como parte de um programa variado da Biograph no Palace Theater de Londres". Essa exibição paralela, mais a aparente falta de sentido autônomo que a película demonstra, indicam a função particularmente publicitária da realização.

De fato, King John representa o ponto de partida para um grande número de filmes, durante o período silencioso, que de algum modo utilizam Shakespeare. Até o surgimento do cinema falado, Kenneth Rothwell (2007: 01) sugere que tenha havido em torno de quinhentas películas que se apropriam do teatro shakespeariano. Ainda que poucos exemplos tenham sobrevivido, esses filmes guardam uma enorme variedade de matizes estilísticos, desde obras mais simples, que captavam suas tomadas de encenações teatrais em cartaz (caso do filme com Beerbohm Tree), passando por filmes que tentavam representar as histórias das peças com o mínimo de coerência diegética, até aqueles que reescrevem os elementos shakespearianos dentro de novos contextos expressivos. Esses filmes utilizam diferentes repertórios cinematográficos, a partir de motivações também diversas. De toda forma, os realizadores tinham que lidar, em cada caso, com o peso que o nome de Shakespeare representava na cultura de fins do século XIX e início do século XX. Sua ressonância no mundo anglófono - comparável apenas às escrituras sagradas do cristianismo ${ }^{2}$ - faz-se presente na vida cotidiana, nos almanaques escolares, nos palcos teatrais, na literatura. A popularização e circularidade de Shakespeare para além do mundo anglófono, impulsionada tanto por influência cultural, quanto pelo imperialismo colonial, certamente referenciam o

\footnotetext{
${ }^{2}$ O comentário de Marlene Soares dos Santos indica o tamanho dessa relação: "a primeira publicação do chamado Mr. William Shakespeare's Comedies, Histories and Tragedies (Comédias, histórias e tragédias do Sr. William Shakespeare), mais conhecido como First Folio (...) se juntaria à Authorised Version of the Bible (A versão autorizada da Bíblia) de 1611 como os dois livros mais importantes da língua inglesa” (2008: 173).
} 
modo como cada cultura se apropria e cria a partir de sua literatura. Desse modo, a análise dos modos de apropriação de Shakespeare no cinema leva em conta as motivações particulares de cada realização, dentro das condições históricas específicas de produção, assim como as intricadas relações que a figura de Shakespeare estabelece no interior de cada cultura.

Uma ressalva, porém, deve ser feita: uma vez que a esmagadora maioria dos livros sobre Shakespeare no cinema é de matriz anglófona (e, quando não, circunscrevem-se a obras desse universo $)^{3}$ e, além disso, o escopo dos filmes que sobreviveram são europeus ou estadunidenses, as obras aqui analisadas vêm, sobretudo, dos Estados Unidos, Inglaterra, França, Itália e Alemanha ${ }^{4}$. Esse recorte indica, de um lado, o problema da preservação de filmes em suas várias instâncias e, de outro, a falta de condições para inferir sobre possíveis realizações em outros países (especialmente fora do eixo EUA - Europa) que tenham se apropriado de Shakespeare durante o período silencioso. Essa lacuna nos demonstra os limites da pesquisa sobre Shakespeare no cinema, especialmente porque os filmes realizados fora do eixo EUA - Europa costumam apresentar estratégias muito singulares de apropriação e adaptação, impondo questões teóricas específicas ao campo de estudo.

Para discorrer sobre os modos de apropriação de Shakespeare no cinema silencioso, é importante caracterizar esse momento específico da história do cinema, apresentando as particularidades da realização de filmes no período que vai do fim do século XIX, até o surgimento e popularização dos talkies, no fim da década de 1920. Para fins metodológicos, vamos dividir esse período em três momentos, cada qual com aspectos sociais, culturais, econômicos e cinematográficos particulares, e que nos auxiliarão na análise dos filmes: o primeiro momento engloba a primeira década do cinema (1895-1906), o segundo trata da década seguinte (1906-1915) e o terceiro vai até 1927, ano do primeiro filme shakespeariano a sincronizar imagem e som de forma bem sucedida: The Merchant of Venice, um filme curto de dez minutos, dirigido por Widgey R. Newman e sonorizado pelo equipamento da $D e$ Forest Phonofilms.

\section{O primeiro cinema $(\mathbf{1 8 9 5 - 1 9 0 7 )}$}

\footnotetext{
${ }^{3}$ Ball (1968) já comentava esse problema.

${ }^{4}$ Boa parte dos filmes é de difícil acesso. Alguns deles foram editados em DVD, outros estão disponíveis na Internet, em sites como os do American Film Institute, British Film Institute, Online Film Collection e Internet Movie Pictures Archieve.
} 
A primeira década do cinema é um período de grande diversidade de experiências, englobando várias formas de utilização da captação e projeção de imagens em movimento, dentro de espaços públicos e privados os mais diversos. De fato, até se conformar no tipo de espetáculo que se consolidou posteriormente - a exibição pública de um longa-metragem, com duração média de cento e vinte minutos -, o cinema em seus primórdios integrava e se misturava a outros tipos de entretenimento, como circo, pantomima, dança, malabarismo, prestidigitação, bizarrias, etc. Os filmes, portanto, faziam parte de programas maiores - dos quais não costumavam ser os protagonistas - e foram se integrando a esse universo cultural ligado às classes mais populares, junto ao centros urbanos industriais que proliferavam no início do século XX. "Como tudo o que pertence à cultura popular, ele [o cinema] formava também um outro mundo, um mundo paralelo ao da cultura oficial, um mundo de cinismo, obscenidades, grossuras e ambigüidades, onde não cabia qualquer escrúpulo de elevação espiritualista abstrata" (Machado, 2007: 73).

A principal característica desses primeiros filmes - em geral, compostos de apenas uma tomada - reside no fato de serem "atrações autônomas, que se encaixavam facilmente nas mais diferentes programações" (Costa, 1995: 16). Isso significa que os filmes concatenavam pouca ou nenhuma cadeia narrativa lógica, guardando-se apenas a mostrar uma ação, um evento, um corpo, uma gag. Esses filmes, além de fazerem parte de programas mais amplos (não restritos à exibição cinematográfica), também não proporcionavam o envolvimento narrativo-ilusionista que mais adiante caracteriza o cinema clássico-narrativo (é comum nesses filmes, por exemplo, que os personagens olhem diretamente para a câmera e se enderecem ao espectador, algo que o cinema clássico iria abolir).

Nesse período, os filmes realizados ainda não buscam marcadamente matrizes literárias e teatrais canônicas como fonte. De fato, o sistema de referências que influencia a criação passa não pelos cânones da literatura e do teatro burgueses, mas pelas formas populares de encenação, especialmente o circo e o teatro de variedades. Embora a ligação mais direta fosse com o teatro e a literatura populares, alguns filmes desse período já se apropriavam de Shakespeare. A principal característica dessas obras é a celebração de momentos famosos das peças, apresentando-os fora de seu contexto diegético específico. Devido à falta de uma estrutura narrativa e, também, à restrição de tamanho (uma peça de Shakespeare durava no mínimo três horas, e os primeiros filmes não mais que alguns minutos), dominava nessas películas a exibição de ações que, em geral, prescindiam das palavras, como as tradicionais cenas de duelo. É desse espectro que surge o segundo filme shakespeariano de que se tem notícia, Le Duel d'Hamlet (1900), dirigido por Clément Maurice 
e protagonizado por Sarah Bernhardt e Pierre Magnier. No trecho do filme que sobreviveu, a câmera estática nos mostra uma sala e um pano teatral ao fundo, com desenhos de pilastras que, no conjunto, remetem a um palácio. Hamlet (Sarah Bernhardt) e Laertes (Pierre Magnier) se posicionam para duelar, como na cena final da tragédia de Shakespeare. Após uma primeira investida sobre Laertes, Hamlet é alvejado e cai, segurado por oficiais da guarda que, em seguida, pegam o corpo (já morto), carregam-no sobre os ombros e saem de quadro. Tudo o mais é esquecido: Cláudio e Gertrudes não aparecem, não há adagas envenenadas, nem o monólogo final de Hamlet. O que importa é o combate, o fato em si, a morte.

Esse filme foi produzido, junto a outros, para a Phono-Cinéma-Théâtre, empresa que abriu em 1900 durante a exposição universal de Paris. Os filmes foram realizados por Clément Maurice, fotógrafo e antigo colaborador de Auguste Lumiére, e pelo produtor Henri Lioret, num sistema que tentava sincronizar o projetor cinematográfico com um fonograma. Além de Hamlet, Maurice realizou também um Romeo et Juliette, no mesmo ano e com o mesmo sistema de sonorização, mas não há registro sobrevivente. É provável que, na exibição original de Le Duel d'Hamlet, o som sincronizado tenha sido o dos choques entre as espadas, mas na cópia que restou há um trecho musical extradiegético.

O que parece relevante perceber nesse filme - bem como nos demais realizados no período - é exatamente o regime de mostração que caracteriza a abordagem sobre a fonte teatral. Num momento em que não podemos necessariamente falar de adaptação, o procedimento de levar Shakespeare às telas se define pelo efeito de novidade e surpresa que os primeiros filmes possuem, em geral em conexão com encenações teatrais que ocorriam concomitantemente à exibição das películas. É o caso, por exemplo, do filme The Tempest (1904), dirigido por Charles Urban e estrelado por Sir. Herbert Beerbohm Tree. No mesmo ano, o ator encenava a peça no His Majesty's Theater, numa jornada muito bem sucedida. $\mathrm{O}$ tema da filmagem, a cena do naufrágio, resultou exatamente da tentativa de dar mais efeito visual à encenação da peça. Ainda nesse período, vale citar dois realizadores e suas obras a partir de Shakespeare, não exatamente por se tratar de filmes que apresentam mudanças estruturais em relação aos já citados, mas pelo destaque que os realizadores possuem na história do cinema. O primeiro é George Méliès, que teria realizado, em 1901, uma paráfrase de Romeo and Juliet (Nobre, 1964: 23), e, em 1907, Hamlet e Shakespeare écrivant Jules César. Dos filmes de 1907, o primeiro, com feição bastante teatral, mostrava a cena do cemitério e o aparecimento do fantasma (bem no estilo fantástico de Méliès) e o segundo apresentava o próprio diretor interpretando Shakespeare enquanto escrevia o assassinato de Júlio César. 
O segundo destaque é G. W. Britzer, que em 1905 realizou o filme Duel Scene from Macbeth. Britzer foi um importante fotógrafo do cinema silencioso, que começou a trabalhar na área com William Dickson (em Dancing Darckies, de 1896) e se notabilizou por participar de inúmeros filmes de D.W. Griffith, com destaque para os clássicos Judith of Bethulia (1914), The Birth of a Nation (1915) e Intolerance (1916). O filme foi produzido pela American Mutoscope \& Biograph Co., e mostra o momento em que Macbeth se confronta com o jovem Siward e, em seguida, seu duelo final com Macduff. Como tal, destaca novamente a principal característica dos filmes shakespearianos realizados no primeiro cinema: são recortes arbitrários nos entrechos das peças, capturando apenas momentos de embate corpóreo, de catástrofes naturais ou mesmo de aparições fantasmáticas, enfatizando o efeito de choque visual, de atração, que é a marca do cinema nesse período.

Com a ausência ontológica de diálogos e com o ainda pouco (ou nenhum) encadeamento narrativo, Shakespeare surge nesses filmes com uma dupla motivação: de um lado, a vinculação imediata com espetáculos teatrais em cartaz durante a exibição dos filmes, o que endossa tanto o seu caráter de vinheta publicitária, quanto a utilização do cinematógrafo como parte da cena teatral (caso de The Tempest, com Beerbohm Tree); e, de outro lado, a importância da imagem de Shakespeare como signo de respeitabilidade social, a que o filme diretamente se vincula (algo que vai se radicalizar no período seguinte).

\section{Rumo à narratividade (1908-1915/16)}

A primeira mudança estrutural no cinema, que impulsionou o filme narrativo, foi nos lugares privilegiados de exibição. O surgimento e, principalmente, a viabilização comercial de salas específicas tornou o espetáculo cinematográfico em um evento per se. Gradativamente, os filmes foram deixando os vaudevilles, onde dividiam o palco com outras atrações, e se aglutinaram em lugares dedicados apenas à exibição de filmes, cujo principal expoente foram os nickelodeons, salas próprias de cinema cuja entrada valia um níquel.

O sucesso lucrativo dos nickelodeons - que passaram a se proliferar sem controle chamou a atenção das autoridades e da elite burguesa, que iniciaram campanhas em favor do controle social e da moralidade. Era comum o consumo de bebidas alcoólicas, o que não raro levava a brigas e confusões, tornando os nickelodeons lugares mal vistos pela cultura oficial. Isso incitou um movimento do poder público, que passou a proibir os filmes e fechar locais de exibição. "Em toda parte, eliminou-se a venda de bebidas alcoólicas, censuraram-se vários gêneros de filmes, purificou-se o ambiente de todas as excentricidades, na tentativa de domar 
as pulsões que emergiam nesses lugares e assim atrair um público mais familiar" (Machado, 2007: 82). Essa campanha contra a promiscuidade do cinema exigiu uma resposta das companhias produtoras, temerosas ante a proibição de filmes e o fechamento de salas. Em 1908, elas criaram um órgão de autorregulação chamado Motion Pictures Patent Company (MPPC), cujo objetivo era "atrair as classes médias 'transformando o cinema no divertimento de todas as classes sociais', e não mais no chamado 'teatro de operários'. Em 1909, a MPPC propagandeava seus filmes como 'divertimentos morais, educativos e são'" (Costa, 1995: 30).

A necessidade de atrair a elite burguesa, seu poder aquisitivo e sua respeitabilidade cultural encaminhou o cinema decisivamente rumo à narratividade. Uma estratégia utilizada nesse momento foi buscar matrizes no teatro e na literatura da cultura oficial, adaptando os "clássicos" da literatura. Foram inúmeras adaptações de Charles Dickens, Honoré de Balzac, Émile Zola, Mark Twain, Victor Hugo, Alexandre Dumas e, claro, William Shakespeare. Esses filmes - embora a referência literária garantisse o envolvimento inicial com o espectador letrado - não conseguiam articular uma narrativa clara, que prescindisse de um comentador externo ou de extensos letreiros explicativos. Isso porque, mesmo nesse período, o cinema estava ainda marcado pela estética de atrações, que vinha do vaudeville, e, com isso, "favorecia mais 'os efeitos espetaculares ou as ações físicas do que as motivações psicológicas' individuais que apareciam nos dramas burgueses e precisavam ser representadas nas telas" (Ibidem: 31). Os diversos filmes shakespearianos realizados nesse momento demonstram essa busca constante por um desenvolvimento narrativo - nem sempre bemsucedido - rumo à constituição de uma história completa, com início, meio e fim.

O número de obras realizadas supera em muito a década anterior e, de fato, a posterior também. É precisamente entre 1908 e 1916 que se encontra o maior escopo de filmes shakespearianos: só em 1908, temos quase vinte filmes catalogados (fora os que se perderam ou dos quais não há registro). Os países produtores mais destacados foram os Estados Unidos, a Itália, a Inglaterra e a França, embora haja registro de filmes da Alemanha (Ein Sommernachtstraum in unserer Zeit, dir. Stellan Ryen e Macbeth, dir. Ludwig Landmann, ambos de 1908), da Áustria (Othello, 1908, produzido por Pathé Frères) e da Dinamarca (Hamlet, de 1910 e For Abent Taeppe, de 1912, ambos do diretor August Blom).

\subsection{Os casos da Vitagraph e da Thanhouser}

Nos Estados Unidos, nos anos que precederam a Primeira Guerra Mundial, dois estúdios realizaram Shakespeare em larga escala: a Vitagraph Company e a Thanhouser 
Company. A Vitagraph, importante empresa cinematográfica fundada em 1897 por J. Stuart Blackton e Albert E. Smith, começou em 1908 uma série de filmes shakespearianos. Encabeçados por Blackton e contando com atores como Charles Kent, Florence Lawrence, Paul Panzer, William Ranous, Julia Swayne Gordon e Maurice Costello, as adaptações da Vitagraph foram largamente distribuídas e tratavam-se, em geral, de filmes curtos de um rolo, que, diferentemente dos exemplos anteriores - com sua retórica de mostração -, já utilizavam a câmera como artifício da narrativa, movendo-a em diferentes posições e articulando os planos de forma a criar uma coerência diegética: no Romeo and Juliet (1908), com Paul Panzer e Florence Lawrence, há em torno de dezessete posicionamentos de câmera diferentes e uma edição já articulando a inteligibilidade da história.

Entre 1908 e 1916, a Vitagraph produziu os seguintes títulos: Antony and Cleopatra, As You Like It, A Comedy of Errors, Julius Caesar, King Lear, Macbeth, The Merchant of Venice, A Midsummer Night's Dream, Othello, Richard III, Romeo and Juliet e Twelfth Night, além de alguns filmes que se apropriavam de Shakespeare para, deliberadamente, reescrever os elementos diegéticos em novos contextos expressivos: A Midwinter Night's Dream (realizado dois anos antes, 1906), Cardinal Wolsey (1912), Indian Romeo and Juliet (1912) e Freddy versus Hamlet (1916). A realização dessas obras indica um interessante procedimento que, em muitos casos posteriores, torna-se fundamental na transposição de Shakespeare para o cinema nos anos seguintes : a inserção da estrutura da peça em um novo ambiente, que pode ser tanto cultural, geográfico e linguístico, quanto de gênero e estilo. É através precisamente da análise desse procedimento que podemos entender, por exemplo, as adaptações transnacionais e transculturais de Shakespeare, bem como sua apropriação em tons de paródia e pastiche.

A Thanhouser Company, uma produtora menor que a Vitagraph, produziu também obras relevantes para entender o papel de Shakespeare no cinema silencioso. Embora trabalhando em dimensões comerciais bem distintas - a Vitagraph era uma grande companhia, com ampla distribuição, e a Thanhouser era uma pequena independente -, as duas produtoras utilizaram Shakespeare - bem como outros clássicos literários - num período em que o cinema buscava legitimação social e cultural, na tentativa de ampliar a viabilidade comercial das salas para um público letrado com maior poder aquisitivo.

Entre 1910, o ano de exibição do seu primeiro filme (The Actor's Children), e 1917, ano em que a companhia encerrou suas atividades, a Thanhouser realizou: A Winter's Tale (1910), Romeo and Juliet (1911), The Tempest (1911), The Merchant of Venice (1912), Cymbeline (1913), Two Little Dromios (1914) e King Lear (1916). De todos, certamente, é 
esse último que se destaca, pelo desenvolvimento narrativo, pela atuação dos atores e, por fim, pela variedade de planos e de articulação na montagem. 1916 é, de fato, o ano do terceiro centenário da morte de Shakespeare que, além do King Lear da Thanhouser - e do já citado Freddy versus Hamlet, da Vitagraph -, teve ainda filmes como: Macbeth, da companhia Triangle-Reliance (um filme americano com a presença do pioneiro britânico Sir. Herbert Beerbohm Tree); dois Romeo and Juliet, um de J. Gordon Edwards, com a atriz Theda Bara que mais adiante se tornaria famosa por suas personagens vamp -, e outro de John W. Noble, com as estrelas Francis X. Bushman e Beverly Beane; e a paródia Hamlet Made Over, de Earl Metcalfe, com Clarence Elmer e Billie Reeves. Também na Inglaterra foram realizados nesse ano filmes de expressiva relevância, como The Merchant of Venice, dirigido por Walter West para a Broadwest Company; Love in a Wood, uma apropriação de As You Like It, dirigida Maurice Elvey, com os atores Gerald Ames, Vera Cunningham e Kenelm Foss; e, por fim, a paródia The Real Thing at Least, a partir de Macbeth, de L.C. MacBean, com Edmund Gwenn, Nelson Keys e Godfrey Tearle.

\subsection{O Filme de Arte Europeu}

Paralelamente à explosão do filme shakespeariano nos Estados Unidos - capitaneada pela Vitagraph e pela Thanhouser -, surge na Europa o chamado film d'art, gênero do cinema silencioso cujo objetivo era levar os clássicos teatrais e literários para o cinema que, nessa época, tentava se popularizar na classe média letrada. O gênero surgiu na França, em 1908, porém a forma proposta pelos franceses se desenvolveu com mais sucesso na Alemanha e, principalmente, na Itália. O film d'art estava diretamente relacionado a autores, atores e técnicos que vinham da cena teatral burguesa e - em clara conjunção com o nome dos escritores clássicos que adaptavam - buscavam se aproveitar desse prestígio para tirar proveito econômico do cinema. No geral, porém, esses filmes tinham ainda grande dificuldade de comunicar uma história unitária, que, inclusive, se parecesse minimamente com a fonte literária de que se apropriavam.

O modelo do film d'art realizou algumas obras que se relacionam com o texto de Shakespeare e sua representação imagética de modo muito singular. Se os filmes anglófonos (em especial, os britânicos) demonstram uma necessidade de respeitar a matriz literária, buscando equivalências visuais para a poesia e a narrativa das peças, os filmes nãoanglófonos se valem de maior liberdade tanto para criar uma história basicamente visual afinal, não há diálogo -, quanto para recriar os elementos diegéticos em novos contextos 
expressivos. "O corolário implícito disso era claro: a liberdade contrastante que pode caracterizar os engajamentos de comunidades não-anglófonas com Shakespeare revigorou e encorajou suas interpretações" (Buchanan, 2005: 50).

Na França, de onde surge o film d'art, Shakespeare foi visto em vários filmes, em sua maioria no estilo ostensivamente teatral. Diretores como Henri Desfontaines (oriundo da cena teatral francesa), Ferdinand Zecca (homem de confiança de Charles Pathé), Henri Andréani (conhecido pela realização de filmes com temas religiosos) e André Calmettes (a figura central do film d'art francês, desde sua criação), realizaram filmes shakespearianos entre 1909 e 1914: Macbeth (1909, dir. André Calmettes), Le Song d'une Nuit d'Été (1909, com George Footit e Stacia Napierkowska), Hamlet (1909, com Jean Mounet-Sully), Antoine et Cleopâtre (1910, dir. Henri Andréani e Ferdinand Zecca), La Mégère Apprivoisée (1911), Falstaff (1911) e Shylock (1913), esses últimos de Henri Desfontaines.

A presença de atores e atrizes famosos no ambiente teatral parisiense também endossava o apelo atrativo e a vinculação com o mundo artístico burguês. Figuras como Jean Mounet-Sully (e seu irmão Paul Mounet-Sully), Jeanne Delvair, Madeleine Roch, Phillipe Garnier, Jean Jacquinet e Émile Dehelly fizeram esse trânsito dos palcos para as telas. Nesse momento, os filmes ampliavam o seu repertório estilístico, a sua gramática narrativa e mesmo o seu tamanho. Também era uma época em que as salas de cinema se elitizavam: se, de um lado, os nickelodeons precisavam ajustar e domesticar suas formas de exibição, de outro lado, começavam a surgir locais mais nobres, como os Palácios, que ostentavam arquitetura e estrutura cênica semelhantes a dos mais nobres teatros burgueses, com palco italiano. Esse é um movimento amplo, que atravessa tanto a Europa quanto os Estados Unidos - e, em menor escala, diversos países ao redor do mundo. Na Inglaterra, por exemplo, a popularização do film d'art - junto à elitização das salas de cinema - influenciou o crescimento do filme shakespeariano.

Desse momento, vale destacar dois realizadores ingleses: o primeiro é William George Barker, que realizou o primeiro filme em 1910, uma versão de Hamlet com o ator Charles Raymond. No entanto, sua obra mais interessante é Henry VIII, uma superprodução de 1911 com o pioneiro Sir. Herbert Beerbohm Tree - que consta ter recebido exorbitantes mil libras pela atuação -, além de Arthur Bourchier e Violet Vanbrugh. Barker aproveitou parte da estrutura da encenação teatral da peça, que ocorria no Her Majesty's Theatre e, a partir dela, criou uma obra grandiosa, com vários atores e cenas.

O segundo realizador foi Frank R. Benson, um importante ator e diretor teatral que por muito tempo foi responsável pelo festival de teatro em Stratford-upon-Avon (cidade natal de 
Shakespeare). A primeira incursão de Benson e sua companhia no cinema foi Richard III, em 1911, com uma estética ainda bastante teatral (tanto na atuação quanto na mise-en-scène), composto de longos planos - um por cada cena - e uma câmera estática posicionada no fundo de uma plateia. Além desses filmes, Benson realizou Julius Caesar, Macbeth e The Taming of the Shrew, todos de 1911 e com atores de sua companhia, como James Berry, Alfred Brydone, Guy Rathbone, Murray Carrington e Constance Benson, esposa do diretor.

Se na Inglaterra o filme shakespeariano tentava lidar com a herança cultural da matriz literária, e se na França o chamado film d'art foi originalmente concebido, na Itália o gênero enfim se tornou popular e grandioso. A principal produtora nesse momento era a chamada Film d'Arte Italiana, uma subsidiária da francesa Pathé Frères, especializada particularmente na adaptação de clássicos literários. Fundada em 1909, a produtora italiana logo se notabilizou por adaptações de Shakespeare, em especial aquelas em que a trama se passa na Itália (Julius Ceasar, Romeo and Juliet e Othello), porém não restrito a esses: as inúmeras adaptações de Hamlet ajudam a endossar isso, como nas versões de 1910, dir. Mario Caserini, 1914, dir. Arturo Ambrosio e 1917, dir. Eleuterio Rodolfi.

Também se destacaram outras duas companhias italianas: a Società Italiana Cines e a Società Anonima Ambrosio. Ambas as companhias realizaram filmes a partir de peças que se passam na Itália, como: Otello (1906, dir. Mario Caserini e Gaston Velle), Romeo e Giulietta (1908, dir. Mario Caserini), Marcatonio e Cleopatra (1913, dir. Enrico Guazzoni) e Cajus Julius Caesar (1914, dir. Enrico Guazzoni); e o famoso Otello (1914, dir. Arrigo Frusta), da Ambrosio, filmado em Veneza e que foi mundialmente distribuído com a alcunha publicitária de trazer a tragédia do Mouro "como o Mestre [Shakespeare] teria desejado".

A principal característica desses filmes italianos é uma contraditória vinculação a um discurso de fidelidade em relação à matriz teatral: se, por um lado, havia um destaque à fidelidade geográfica dos filmes, que levavam as histórias para os exatos locais onde elas ocorrem nas peças, por outro lado, havia a liberdade em relação ao texto, proporcionando uma maior criatividade na hora de imaginar as cenas para o novo meio do filme silencioso. Comparando duas versões de Hamlet, realizadas na Inglaterra e na Itália ${ }^{5}$, Buchanan sugere que a versão italiana, "diferentemente do paralelo britânico, é menos um ato de preservação do que de criação. Como resultado, seu pensamento interpretativo é muito claramente discernível na especificidade de sua construção técnica" (Ibidem: 58).

\footnotetext{
${ }^{5}$ Hamlet (1913, dir. Hay Plumb) e Amleto (1917, dir. Eleuterio Rodolfi).
} 
É importante perceber que a segunda década do cinema, período em que tanto os locais de exibição se tornaram mais organizados, quanto a narrativa cinematográfica se estruturou numa gramática própria, é também o de maior quantidade de adaptações shakespearianas. Uma razão para isso está no movimento de elitização do espetáculo cinematográfico, que recorre aos clássicos literários a fim de legitimar o novo meio. Isso impulsionou a criação e o estabelecimento do film d'art, num momento em que os Palácios (nome cuja referência imperial não esconde a ambição dos exibidores) se tornavam locais de exibição que cada vez mais atraíam a classe média letrada.

Ao fim desse período, com a explosão da Primeira Guerra Mundial na Europa, outras questões entraram na pauta cinematográfica, diminuindo a produção de filmes no continente. Mesmo com o fim do conflito, a adaptação de Shakespeare nunca voltou à profusão desse período, tornando mais esparsas - ainda que continuamente presentes - essas adaptações. Em termos estilísticos, as mudanças também se aguçaram: o cinema desenvolveu técnicas narrativas que se consolidaram internacionalmente, abrangendo as capacidades expressivas do meio (ainda sem o recurso dos diálogos) e ampliando o espetáculo fílmico em suas dimensões. Cada vez mais, os filmes shakespearianos não podiam se limitar a apenas mostrar ações, situações e cenas célebres, seja numa estética teatral, seja numa construção mais realista. Os filmes deviam construir uma história unitária com começo, meio e fim, que fosse inteligível independentemente das matrizes literárias que lhes serviam de fonte. E, antes da revolução mais radical do cinema sonoro, alguns longas-metragens silenciosos foram realizados, filmes que levaram Shakespeare ao cinema a dimensões jamais alcançadas.

\section{Fidelidade e Transgressão: Shakespeare silencioso na Alemanha}

Na Alemanha do entreguerras, as condições para a reconfiguração de uma indústria cinematográfica ganharam contornos muito específicos. A República de Weimar, instaurada logo após o fim da Primeira Guerra Mundial, tentava reconstruir o país em um regime agora parlamentarista democrático, dentro das condições nada favoráveis do Tratado de Versailles. Os primeiros anos de trabalho nessa reconstrução logo seriam suplantados por enorme desemprego, inflação incontrolável e o recrudescimento de posições políticas autoritárias e movimentos de extrema-direita. Até 1933, ano da ascensão do partido Nacional-Socialista ao poder, com a nomeação de Adolf Hitler como chanceler do parlamento, o cinema de Weimar experimentou uma grande expansão, tanto interna quanto externamente, internacionalizando 
sua distribuição numa época em que, pela ausência de diálogos e pelo apelo a uma narrativa basicamente visual, os filmes não tinham tantos problemas em quebrar as barreiras linguísticas e ser consumidos em outros países.

Foi nesse contexto que surgiu o chamado Expressionismo Alemão. Apesar de resistir a definições totalizantes e guardar particularidades autorais, o Expressionismo Alemão pode ser entendido como um tipo de cinema que, semelhante ao drama e à pintura expressionistas, utilizava tipos sociais ao invés de personagens individuais psicologicamente definidos, cujos conflitos internos eram projetados numa mise-en-scène e num décor que associavam a distorção das linhas e das formas com as sensações de loucura, desejo e medo que afligiam os personagens. O movimento teve como marco inicial o lançamento de Das Cabinet des Dr. Caligari, de Robert Wiene, em 1920, filme seminal na popularização do movimento e, inclusive, na internacionalização do cinema alemão em um mercado dominado pelos filmes americanos, franceses e ingleses.

Nesse mesmo ano, o diretor sueco Sven Gade juntou-se à sua conterrânea Asta Nielsen, já então uma celebridade no mundo do cinema, para realizar uma das versões mais transgressoras de Hamlet. Utilizando como fonte não apenas o texto da peça de Shakespeare, mas um conjunto de referências que vai do Saxo Grammaticus - livro de lendas nórdicas de onde Shakespeare teria tirado a história do príncipe dinamarquês - a uma controversa monografia do escritor estadunidense Edward P. Vinings, o filme de Gade, Hamlet: The Drama of Vengeance, embora remonte à tradição de mulheres desempenhando o papel do príncipe - como fez Sarah Bernhardt no primeiro Hamlet filmado, em 1900 -, transcende esse viés ao encenar o protagonista, dentro da diegese, como uma mulher travestida em homem.

A trama do filme é um emaranhado de reviravoltas com o intuito de mostrar que, na verdade, Hamlet era uma mulher. A história começa bem antes que a peça de Shakespeare, no fim da guerra entre a Dinamarca e a Noruega. O Rei Hamlet está em plena batalha contra Fortimbrás. Enquanto isso, Gerturdres está grávida e dá à luz, na ausência do Rei. O casal há tempos tentava gerar um sucessor para o trono, portanto, o nascimento da criança é um fato político da mais alta importância. No entanto, nasce uma menina e Gerturdres, temente de o Rei não sobreviver à batalha, anuncia o nascimento de um filho homem. Com isso, ela estaria imune ao ataque da nobreza que, na ausência de um varão de sangue real, poderia reivindicar o trono. O Rei volta para casa, e, mesmo surpreendido pelo estratagema de Gerturdres, não desfaz a mentira e continua criando Hamlet como um homem. Passam-se os anos e a próxima sequência mostra um Hamlet jovem e andrógino na universidade de Vintenberg, onde estuda com Horácio - a quem o príncipe devota uma mal resolvida e agônica afeição. $\mathrm{Na}$ 
universidade, ele recebe a notícia do falecimento do seu pai e deve imediatamente retornar a Elsinore.

Transformar Hamlet em mulher buscaria resolver uma série de sugestões que, no texto de Shakespeare, aparecem sem uma resposta clara: a relação homoafetiva entre Hamlet e Horácio, o relacionamento complicado do príncipe com Ofélia, a inabilidade para a ação, o excesso de atitudes reflexivas, a visão quase ufanista que tem do pai e os atritos com a mãe (que, na versão do filme, teria de fato tido um caso com Claudius antes da morte do rei). São essas sugestões no escopo da diegese, que motivam o filme de Sven Gade a "resolver o mistério", a construir uma explicação plausível (ainda que extremamente criativa) para os problemas internos da personagem shakespeariana. Como acrescenta Kenneth Rothwell, “o príncipe travestido incorpora toda a ambiguidade do leitmotiv da peça acerca da inter-relação entre ilusão e realidade (...), e um Hamlet que é internamente "mulher" e externamente "homem" joga com a obsessão da peça com atrasos, hesitações e indecisões" (Ibidem: 23).

De fato, os méritos do filme de Gade, juntamente à interpretação de Nielsen (mais contida e menos histriônica que a tradição de Shakespeare no filme silencioso), residem, primeiramente, na forma como o filme acrescenta uma leitura crítico-analítica para a peça; nesse sentido, podemos dizer que esse filme funciona como um metatexto, ou seja, um exercício interpretativo a partir de Hamlet. Vale destacar, no entanto, que esse aspecto hermenêutico do filme de Gade não o torna uma obra pedagógica e, ainda que o filme careça de muitas cartelas explicativas, sua narrativa se desenvolve clara e teleologicamente.

Além disso, outro mérito do filme é o modo como se relaciona com a literatura de Shakespeare, mostrando que o processo de adaptação do cânone não precisa passar, necessariamente, pela busca ensandecida de uma fidelidade inalcançável ao texto fonte, mas pelo diálogo com outros textos e outras perspectivas, a ponto de inferir, acrescentar e mesmo questionar o cânone. Essa atitude, embora não seja dominante na história de Shakespeare no cinema, vai aparecer outras vezes a partir de então. As adaptações transculturais, de gênero, raça e nação, as leituras políticas, as apropriações pós-coloniais e as paródias pós-modernas, que hoje se tornaram mais corriqueiras na agenda das produções cinematográficas (dentro ou fora dos centros hegemônicos), encontram em Hamlet: The Drama of Vengeance, certamente, um ancestral remoto cujos procedimentos estilísticos e cuja postura face ao cânone ainda servem de influência.

\subsection{Um Othello em Weimar}


Em 1922, a Alemanha produziu outro longa-metragem a partir de Shakespeare: Othello, de Dmitri Buchowetzki, protagonizado por duas estrelas do cinema de Weimar: no papel de Othello, Emil Jannigns, um dos principais atores dos anos 1920, em filmes como Anna Boleyn (1920) e Das Weib des Pharao (1922), de Ernest Lubitsch, Herr Tartüff (1925) e Faust (1926), de F. W. Murnau, The Way of All Flesh (1927, dir. Victor Fleming), pelo qual ganhou um Oscar de melhor ator e, finalmente, Der Blaue Engel (1930, dir. Josef von Sternberg), na sua mais famosa atuação; e, no papel de Iago, Werner Krauss, também uma grande estrela do cinema alemão da época, especialmente, por sua atuação no filme seminal do Expressionismo Alemão, Das Cabinet des Dr. Caligari, de Robert Wiene.

Em termos de gramática cinematográfica, Othello se destaca pela utilização às vezes exageradamente enfática dos close-ups, um procedimento cujo intuito é "causar uma sensação de embaraçado intrometimento na grotesca intimidade dessas trocas particulares e manter o equilíbrio do momento pré-climático por ousado e longo período de tempo" (Rothwell, Ibidem: 65). Embora as atuações ainda guardem uma tonalidade teatral bastante perceptível (especialmente pelo exagero nas expressões faciais e nos movimentos corporais), uma virtude do filme está no trabalho de câmera e em uma mise-en-scène mais realista, que insere o drama de ciúmes entre o mouro veneziano e sua esposa, Desdemona, numa dimensão política que transcende a própria peça nesse aspecto. Por exemplo, a partida de Othello para o Chipre, no início da peça, não ocorre simplesmente porque ele é chamado pelo Senado para tal, mas por toda uma sublevação popular demandando que ele tome partido da sua causa. Isso se manifesta novamente no fim do filme, quando a população se revolta com a prisão de Othello, por ter assassinado Desdemona. Essa ligação entre tragédia interpessoal e drama político que Shakespeare tão bem sintetizou em suas principais peças - se articula no filme como um catalisador para o efeito de realismo almejado. Variar entre o mais íntimo e o mais público (o pessoal e o social) funciona como a manipulação do olhar da câmera, entre o mais próximo e o mais amplo (close-ups e planos gerais), algo que o filme de fato materializa na sua mise-enscène.

A principal cena do filme, certamente, é a que Iago mostra o lenço a Othello, como prova da suposta traição de Desdemona. Utilizando uma variação de planos detalhes, closeups e planos mais abertos com profundidade de campo, a cena vai progressivamente enredando Othello - e, por consequente, o espectador - dentro da trama urdida por Iago. A carência dos diálogos, que na peça desempenham uma função crucial na articulação da cena, é suprida por algumas poucas cartelas e pela encenação dos corpos dos personagens e dos objetos cênicos. Tanto Jannings quanto Krauss manifestam bastante os efeitos dramáticos 
através dos seus corpos e gestos, algo que, particularmente na cena do lenço, deve ser elevado e intenso, pois, de um lado, tem que suprimir a carência da poesia shakespeariana e, de outro lado, tornar inteligível uma linha narrativa que vai da dúvida e da angústia, passa pela urdidura planejada por Iago e chega na resolução intempestiva de Othello de matar a esposa.

Nesse sentido, a escolha de Werner Krauss para interpretar Iago não parece nem um pouco casual. Pelo contrário, o modo como sua figura é associada a uma entidade de horror e medo - cuja matriz está, sem dúvida, na sua performance como o Dr. Caligari -, acrescenta à sua interpretação de Iago uma camada de significação que é, nesse sentido, puramente cinematográfica. Os corpos dos atores e os papéis que interpretam criam padrões de significado que são utilizados largamente pela indústria do cinema, influenciando diretamente na espectatorialidade dos filmes. Dessa forma, podemos dizer que a escolha de elenco gera significados expressivos nas obras, uma vez que vinculam os corpos dos atores a certo tipo de gênero e de performance. No caso de Werner Krauss como Iago não é diferente: ao escalá-lo como o vilão mais pérfido das peças de Shakespeare, o filme se vale da associação indireta entre o personagem e o tipo de atuação que caracteriza Krauss. Uma vez que é uma representação visual de uma peça teatral, imagem e performance se juntam na articulação dramática dos planos e na conformação final dos sentidos. Ao materializar isso, Othello se alinha a um modo de conceber a dramaturgia cinematográfica em sua especialidade, considerando os materiais expressivos que lhe são particulares para criar, à sua maneira, conflitos, crises e soluções dramáticas através do uso próprio da imagem em movimento.

\section{Considerações finais}

Ao vermos o caso de Shakespeare no cinema silencioso, deparamo-nos com tentativas que pouco a pouco buscam mobilizar uma narrativa dramática, sem o apelo das palavras algo que tem importância fundamental no processo de canonização de sua literatura. Essa mobilização transita entre uma mera renderização visual de cenas e momentos célebres das obras, até procedimentos de adaptação e ressignificação que colocam as tramas shakespearianas em outros domínios de ordem cultural e estética.

Uma vez que os filmes de Sven Gade e Dmitri Buchowetzki guardam essa liberdade expressiva em relação ao texto shakespeariano - impondo-lhe novos sentidos dentro de uma nova forma audiovisual - eles servem historicamente também para demarcar o fim de uma época. Com o surgimento do cinema falado, as adaptações de Shakespeare caíram vertiginosamente em termos quantitativos e, entre o primeiro longa-metragem shakespeariano 
falado (The Taming of the Shrew, 1929, dir. Sam Taylor) e o fim da Segunda Guerra Mundial, o teatro de Shakespeare sofreu para ser viável economicamente no cinema, e, em termos estilísticos, para balbuciar suas primeiras palavras em um meio que cada vez mais buscava definir a sua especificidade. Para entender a história que se segue, é, portanto, fundamental compreender esse primeiro momento, em que o cinema silencioso tentou, de várias formas, incorporar Shakespeare à agenda de suas preocupações, algo que, sem dúvida, auxiliou na popularização do bardo inglês em plateias ao redor do mundo, fazendo-o dar o salto definitivo do teatro e da literatura, para a vida e a experiência cotidiana de um público cada vez mais mediado pelo audiovisual.

\section{Referências bibliográficas}

BALL, Robert Hamilton. Shakespeare on Silent Film: a Strange Eventful History. New York: Theatre Art Books, 1968.

BUCHANAN, Judith. Shakespeare on Film. New York: Longman-Pearson, 2005.

COSTA, Flávia Cesarino. O Primeiro Cinema: Espetáculo, Narração, Domesticação. São Paulo: Editora Scritta, 1995.

LEÃO, Liana de Camargo e SANTOS, Marlene Soares dos (org.) Shakespeare: sua época e sua obra. Curitiba: Editora Beatrice, 2008.

MACHADO, Arlindo. Pré-cinemas e pós-cinemas. Campinas, SP: Papirus, 2007.

NOBRE, F. Silva. Shakespeare e o cinema. Rio de Janeiro: Ed. Pongetti, 1964.

ROTHWELL, Kenneth. A History of Shakespeare on Screen: a Century of Film and Television. Cambridge: Cambridge University Press, 2007. 